\title{
Reproducing Gender? Intergenerational Links and the Male PE Teacher as a Cultural Conduit in Teaching Physical Education
}

\author{
David Brown \\ Exeter University
}

\author{
John Evans \\ Loughborough University
}

\begin{abstract}
Drawing on illustrations from a recent life history study that focused on male student teachers as they negotiated their way through a 1-year postgraduate certificate in education (PGCE) physical education teacher training course at a university in England, this paper explores how teachers are implicated in the social construction of gender relations in teaching physical education and school sport. The perspective forwarded is that the embodied gendered dispositions student teachers bring into the profession constitute a powerful influence on their professional behavior, and that the development and legitimation of these dispositions might be traced to key relationships with other physical education and coaching professionals. In so doing, we identify key moments in a process of cultural reproduction and conclude that teachers might be viewed as intergenerational living links or cultural conduits in the construction and transmission of particular gender orientations and practices in the profession. We conclude that future research needs to be intergenerational in focus if we are to better understand how these links act as channels in reproducing gender relations and how we might rupture and challenge them.
\end{abstract}

Key Words: sport, occupational socialization, embodiment, identity construction, social reproduction and change, living links

"Who teaches our children and what do they believe are important questions for any society to address." (Schempp \& Graber, 1992, p. 345)

Gender, especially gender differentiation, has long been an issue for physical education specialists in schools and initial teacher education (ITE) in the U.K. and elsewhere (Flintoff, 1993; Penney \& Evans, 2002; Scraton, 1993). Yet despite significant innovation in the curriculum of physical education, school sport, and ITE since the introduction of a national curriculum in 1998 and a subsequent deluge of central gvernment-driven policy texts requiring changes in the curriculum of ITE physical education (ITEPE), it seems very little has changed in the U.K. in

David Brown is with the Qualitative Research Unit, School of Sport and Health Sciences, Exeter University, Exeter, EX1 2LU, U.K.; John Evans is with the School of Sport and Exercise Sciences, Loughborough University, Loughborough, LE11 3TU, U.K. 
terms of the gendered nature of the "physical education ritual" (Hargreaves, 1986). Arguably, the education system in England and Wales has been less responsive to social change inspired by the second wave feminism of the 1960s and 1970s than elsewhere. In other countries, for example Title IX in the U.S. and equality-ineducation legislation in France, there is now a guarantee of access to a common physical education in law, although even here the struggle for gender equity is far from over (see Bourdieu, 2001; Nilges, 1998).

Sociological research has consistently highlighted the social and cultural inertia in gender relations in physical education classrooms in the U.K. (e.g., Delamont, 1998; Penney, 2002; Rich, 2001; Talbot, 1993; Williams \& Bedward, 2001). Dominant hegemonic forms of masculinity prevail today as they have done so throughout the development of the subject in the U.K. (Kirk, 2002). Indeed, gender segregation and the differential treatment of boys and girls is often considered socially and culturally legitimate in this subject area, sometimes robustly defended as natural and desirable by politicians, ideologues, and practitioners alike (Hargreaves, 2000).

Although some change has occurred in recent years, with girls gaining increased access to a wider variety of sports (usually to the previously male dominated sports), research in the U.K. suggests that relatively few girls and boys persist with these activities into adulthood and outside of school (Flintoff \& Scraton, 2001; Kirk, 2000; Roberts, 1996). Additionally, while the attrition rate for boys is much lower than for girls, this is perhaps due in part to deep-seated structures of patriarchy in leisure and family life (see Deem, 1986). In boys' physical education and school sport, even less change seems to have occurred, especially in the "top dog" competitive culture that characterizes this social arena (Salisbury \& Jackson, 1996).

Activity provision for boys and their modes of interaction in physical education and sport seem to have remained relatively stable over the last three decades, despite initiatives suggesting that broader and less differentiated cultural practices might be more usefully employed in physical education and sport (Kirk, 1997; Penney \& Chandler, 2000). Research has consistently reported that male physical education and school sport is a culture that legitimates a certain type of "maleness" that both draws from and feeds ideologies of what it is to be a successful heterosexual male in Western physical culture (Light \& Kirk, 2000; Gard \& Mayenn, 2000; Pratt \& Burn, 2000; Swain, 2000). Indeed, some argue that boys' physical culture is becoming even more hierarchical and competitively orientated in response to the increasing colonization of the traditionally male sporting bastions by those few females who brave the transgressions of participating in "male" associated activities (Kenway, 1998; Messner, 1992).

In this paper we cast our gaze on the part played by male physical education teachers in reproducing gender relations and ideologies. Drawing on a critical relational perspective outlined by Wright (1995), we argue that it is important to locate male PE teachers both as persons and professionals in the foreground of analysis when discussing gender construction in physical education and school sport - at the same time treating gender differentiation not just as a technical issue but as an intergenerational relational matter because, as Griffin (1989) points out, this former perspective...

is based on the naïve assumption that once teachers are aware of the errors of their ways and change, the problem will be solved. It's only a matter of 
providing the appropriate instructional resources to help teachers make the transition from gender discrimination and bias to gender fairness. (p. 222)

Naively reducing gender equity to a cognitive, technical issue belies the complexity of gender power relations in society, their embodiment in individuals, and their modes of practical transmission in sport and physical education. Viewing teachers as individuals whose actions are dominated and determined by their cognitive understandings of teaching physical education, in our view, incorrectly assumes a passive, disembodied, and nonmaterial "self" (Sparkes, 1999a). By contrast, a critical relational view contends that patriarchy in the classroom is embedded within the minds and bodies of teachers and pupils sharing a social presence and influencing one another's actions, while using culturally specific gender "norms" as a point of reference (Brown \& Rich, 2002).

Relational views of gender challenge us to reexamine structure/agency, nature/culture, and body/mind dichotomies and consider how masculinities and femininities are constructed in opposition to one another within a broader social context of enduring networks of patriarchal power. In so doing we can acknowledge the implications of these interconnections for social and cultural change. As Edley and Wetherell (1995) point out, the relational nature of men and women (among other social categories) implies that changes to the position of one group will cause ripples, affecting the lives of the other. This sentiment is strongly echoed by Hall (1996), who argues that explanations of women's oppression and subordination in sporting fields are inseparably tied to analyses of men and masculinity. She adds that studies of men, by men, should include examinations of "how male hegemony reproduces unequal gender relations" (p. 45). This view is increasingly reflected in research in the U.K. and elsewhere. As Wright (1999) points out,

Research in North America, Australia and the UK demonstrates that even when this is assumed to be the case the dynamic relationship between the students' and teacher's experiences and expectations produce social practices which construct traditional gender positions for teachers and their students. (p. 184)

Our contention is that if we wish to better understand both the pervasiveness and relative stability of gender-power relations in contemporary physical education, we would do well to consider their implicit and embodied construction and reconstruction across generations of physical education teachers and pupils. As Fernandez-Balboa (1993) contends, physical education teachers, perhaps especially male teachers, are centrally involved in the construction and perpetuation of the hidden curriculum, where we might expect to locate complex processes of gender production and transmission: "The dominant social norms, beliefs and behavioral styles are adopted and transmitted by physical education teachers and teacher educators through a process of professional socialization" (p. 244).

We do not see teachers' engagement with others in their profession as the only experience that shapes their orientation toward physical education and gender: The prevailing sociocultural background, family, and peer-group relations among other influences all provide contexts and resources for individual action. That said, here we are primarily interested in exploring the significance of the relationships these men have experienced in physical education and sport. We focus on three such relationships, or linkages, that we consider central in the process 
of cultural reproduction, illustrating them with reference to data from a recent study of males in ITEPE. The first is the "participant as pupil/teacher link," which focuses on the relationships the participant experienced as a pupil with his physical education teachers. The second is the "student teacher/mentor link," which considers the relationship between the participant as a trainee teacher and his mentors (the teachers appointed by the school to guide him through his school based training). The third is the "second-generation participant as qualified teacher/pupil link," in which we consider the participant's approach to teaching as a novitiate qualified physical education teacher.

In the following we highlight how the male participants in this study acted as cultural conduits, developing and acquiring gendered orientations, beliefs, and capacities (see Evans, Davies, \& Penney, 1996), dispositions which are literally embodied, expressed as part of their pedagogy, and implicitly conveyed to the next generation of pupils. As we will see, this often occurs despite their best intentions to offer a less differentiated pedagogy and to contest conventional gender stereotypes in the curriculum of physical education.

\section{Data and Methods}

The insights presented in this paper are grounded in concepts and data generated from a qualitative, life history study conducted between 1997 and 2001 which explored the significance of embodied masculine identity in becoming a teacher of physical education. A parallel study centered on female student physical educators (see Rich, 2001). Drawing its strategic methodological approach from Sparkes $(1992,1999 b)$, the study focused on collecting the life history "stories" of 8 male student physical education teachers. As Atkinson (1998) contends,

In academe, we have entered the age of narrative. ... Story presents us with a form of knowing that is equally of interest in history as it is in literature as it is in psychology, sociology, and even science. Story gives us lived experience in its purest, rawest form. (p. 74)

Because stories are only representations and the life history approach works with representations of subjectivity as raw materials, as a research method it reveals "like nothing else can, the subjective realm" (Plummer, 1983, p. 14). Lifehistory research data are generated from direct interaction with the participants and focus on the stories they tell. We take a working definition of life history from Watson and Watson-Franke, who consider that life history is "any retrospective account by the individual of his (or her) life in whole or in part, written or in oral form that has been elicited or prompted by another person" (cited in Tierney, 2000, p. 538). The life history method, then, gives access to how social, cultural, economic, and historical forces both frame and are framed by individual lives and how each unique individual generates responses that may either reinforce or challenge the social forces acting upon him or her.

The sampling strategy used in our study is based on the principles of purposeful and criterion-based sampling (Patton, 1990). With purposive sampling the researcher deliberately selects certain processes, sites, events, settings, and individuals because, for a variety of reasons, they are judged to be the most useful sources of information. Here we engaged in theoretical sampling (Burgess, 1982), a form of purposeful sampling that selects critical cases by drawing up criteria 
from the theoretical framework of the study as articulated in part above. We therefore explored the life histories of men with a range of sociocultural backgrounds as they passed through their 1-year postgraduate certificate in education (PGCE) teacher education course at a university in England and beyond into a career in teaching physical education. The PGCE is now the most common route to teaching in the U.K. In recent years government legislation in the U.K. has presaged a transition from the once popular and widespread B.Ed ITE programs, in which academic study and teaching practice in schools was spread concurrently over 3 to 4 years, to the 3 -year specialist academic university degree +1 year PGCE (ITE), in which students spend up to $80 \%$ of their time training in the schools.

The divorce of the academic from the practical and the extended schoolbased element of ITE programs in the PGCE year are, we later suggest, significant factors in the reproduction of social hierarchies and gender relations (Evans, Penney, \& Davies, 1996). Furthermore, the accompanying government rhetoric on education reform in ITE has shifted the emphasis away from teacher education toward teacher training, as reflected in the abolishment of the Council for Accreditation of Teacher Education (CATE) and its replacement with the Teaching Training Agency in the mid-1990s. These are more than merely changes in terminology. The TTA, which is responsible for monitoring standards and implementing policy on ITT (initial teacher training), now promotes teacher training as a practical, pragmatic, technical exercise that is best achieved away from universities. This is the ideological backdrop against which the voices of the students in our study must be heard.

As researchers we are not value-neutral in either our thinking or actions, and for this reason, as numerous methodological commentators point out, the role of the researcher in the research process requires some acknowledgment (Altheide \& Johnson, 1998; Cresswell, 2003; Kvale, 1996). Our concerns over the shift from ITE to ITT outlined above and its connections with the social construction of gender were firmly on our research agenda. However, we set out neither to confirm nor construct any of these concerns in the data; rather, we were primarily interested in exploring connections for their conceptual and practical significance.

Our main motive for the interview-based approach, therefore, was to see it from the participant's perspective, engage in "indwelling" which, as Maykut and Morehouse (1994) point out, "requires the investment of sufficient time to learn the culture, test for misinformation introduced by distortion either of self or of respondents, and to build trust" (p. 29). It should be added that all the participants provided informed consent and were given strict confidentiality within the institution. Furthermore, although in the same institution, we as researchers were not involved with the grading or training of the participants. The date, time, place, and content of the interviews were negotiated with the participants beforehand to give them a sense of control and ownership (see Woods, 1986). These relationships helped establish mutual trust between researcher and participant, develop rapport, and enhance the collection of trustworthy data by removing some potential barriers that might otherwise encourage the participants to say what they felt we wanted to hear (see Moustakas, 1994), or indeed say nothing and withdraw.

We have not provided detailed personal profiles on the 8 participants in this study_-Peter, Derek, Trevor, Alan, Joe, Shaun, Adrian, and Paul (all pseudonyms) as this could compromise confidentiality. However, a brief introduction to those whose life history excerpts are represented here is important and provides neces- 
sary, albeit limited, sociocultural texture to the voices later heard. The participants' backgrounds collectively represent working and middle-class men with rural, suburban, and inner city Northern and Southern English, English Afro-Caribbean, Northern Irish, and Welsh ethnicity. As a group, they reflected the typical age range for a PGCE physical education student entering the profession at ages 21 to 23. Their schooling experiences include state comprehensive grammar schools and private schools, and their sports backgrounds include professional schoolboy football, international athletics, semiprofessional rugby, and club cricket. They all describe themselves as "able all-rounders" in a range of sports and have all performed at the county or above level in their respective areas. Therefore, while we do not intend to imply that this sample represents the greater population of male physical education teachers, our purpose was to explore a diversity of experiences from a variety of backgrounds.

In-depth, semi-structured, and reflexive (Hammersley \& Atkinson, 1983) interviews were conducted before, during, and after their PGCE course that focused on gathering the life stories (see Atkinson, 1998, pp. 41-53) of the participants with a particular reference to the development of their physical self and identity (Sparkes, 1997) over time. The three-part interview process had the objective of addressing the issue of internal consistency (Atkinson, 1998, p. 60) of the data, with participants being asked to review aspects of the stories they had already told; this gave the researcher an opportunity to cross-reference the data on more than one occasion. When there were discrepancies in the stories, participants were asked why they had changed their views and if it had anything to do with the experiences they were accumulating from the PGCE course they were attending.

All the interviews were tape-recorded, transcribed by a third party, and checked for basic accuracy by us (Kvale, 1996). As suggested by Atkinson (1998, p. 57), the transcripts were member checked in that they were made available to the participants for feedback. They were then coded for emergent and conceptual themes (Miles \& Huberman, 1994). Preliminary interpretations were also checked in two ways. First, as both Maxwell (1996) and Creswell (2003) suggest, these interpretations (and the data transcripts) were peer reviewed. Second, elements of the developing interpretations were introduced to participants during the followup interviews, giving a sense of co-authorship (Kvale, 1996). Elsewhere, these qualitative strategies of improving accuracy, reliability, or trustworthiness of qualitative data have also been described as a mutual endeavor (Woods, cited in Sparkes, 1992). Based on the above processes, we concluded that our fundamental interpretations, relating for example to the student-teacher's sense of masculine identity, pedagogical influences, and approaches, were consistent with the participants' own understandings and experiences.

We based the main life history analysis on what Lieblich, Tuval-Mashiach, and Zilber (1998) describe as a holistic content analysis. We explored a number of conceptually driven themes and perspectives toward gender, identity, embodiment, change, and reproduction, as these too emerged within the context of the participants' life story as a whole, thereby attempting to retain a sense of meaning in context, rather than analyzing fragmented, decontextualized extractions. For the purposes of this paper the data are used in an illustrative capacity to convey examples of the "lived" experiences and linkages being articulated. We adopted a "realist tale" writing strategy (Sparkes, 1995) in which, as authors, we distance ourselves from the text and the data become unavoidably refragmented. While 
acknowledging the methodological difficulties associated with this style of representation and the possibilities for other forms of writing in physical education and sport (Sparkes, 2002), we considered it the most suitable method of retaining the focus of this paper, which is to begin building a conceptual picture of male teachers as cultural conduits.

In questioning the underlying epistemological foundationalism of validity in representation, Sparkes (1989) points out that interpretive research must seek judgment on representation that is relevant, "in terms of its own internal dynamic meaning structure" (p. 146). He adds that cognitively, the logico-scientific mode of thinking does not make sense if applied to these internal structures. This is in part because the logico-scientific mode inhibits development of different relationships between theory and data. In order to articulate this relationship, the work of Plummer (2001) is particularly pertinent:

Social science probably proceeds best through some sense of cumulative, if partial generalization-building up ideas and concepts into layers of theory and understanding. . . Theories are simply ways of piecing the world together; though they come in many forms (grand, middle range, grounded; inductive, deductive, abductive; operational, prepositional, systematic, formal) and have many purposes (explanatory, sensitising, connecting). But they always work to provide a link between the very specific and the particular and the more abstract to the general. Life stories are nearly always geared to the more specific and particular and theory gives them a bridge to wider concerns. (p. 159)

Relating Plummer's perspective to this work is important because one of the express intentions in this work is to develop our understandings of the construction of masculinities in and through physical education teachers and teaching. Indeed, Plummer contends that...

Theoretically we can make sense of life stories in three ways:

- To take a story to challenge some overly general theory

- To take a story to illustrate or illuminate some wider theory

- To take a story as a way of building up some wider sense of theory. (p. 159)

\section{The Participant as Pupil/PE Teacher Link: Developing Gender Resources}

Schools, perhaps especially secondary schools, are masculine institutions, structured around dominantly masculine ways of being and acting in the world (Salisbury \& Jackson, 1996). Within them, male physical education and school sport have been identified as bastions for the construction and expression of dominant masculinities (Jackson, 1990; Messner \& Sabo, 1990). Of course male physical culture extends beyond the confines of school physical education and school sport, and an analysis of fathers, brothers, and peers, for example, could add greater breadth and cultural texture to this analysis. However, we focus on the link between physical education teachers and pupils because, without exception, the participants' life histories highlight the significance of this relationship in the reproduction of hegemonic male physical culture. At school their athletic abilities were quite properly noticed, nurtured and celebrated, and they benefited from and 
become centrally involved in the overtly masculine sports culture of the schools they attended. Moreover, this situation placed them in a position to gain cultural access to qualities or gender resources typically exhibited by their male physical education teachers. Getting into this position required commitment and displays of ability, as the following comment by Shaun illustrates:

At school. . . there was about five or six of us who literally had a practice at lunchtime and after school, that was my main reason was for going to school. Yes in the winter it was rugby/ football that it was, and if the football team didn't have a game we were dragged to play rugby, and then in summer it was, we had a very keen tennis teacher, and we used to go before school and at lunchtime and after school.

For Shaun, as for other physically able-bodied peers, this link with the physical education teacher constituted something special, unique, and distinct from the relationship which he had with other teachers, and it had a powerful bearing on his outlook and educational career:

Well as I was, say, there was a very keen tennis teacher who did a lot for us and he was also our football bloke, so we got to know him very well. I haven't seen him for quite a while. But there are some lads who have just arrived here from [school], some Freshers, and they were saying they lived nearer the school than I do and they see more of this particular PE teacher, and he's still doing it and they were saying that I should go and see him.

Evidently Shaun had been implicitly recruited into what Brown (1997) described as the inner sanctum of the physically able and keen young male athletes in the school. The disproportionate amount of time they spent playing sport, both inside and outside of school time, set them apart from their peers both technically and physically. Importantly, as Shaun indicates, they got to know their physical education teacher very well indeed, and the normal relationship between teacher and pupil was transformed into a special relationship as a consequence. Peter elaborates on the nature of this relationship and encapsulates many of the other comments which suggest the efficacy of this intergenerational link:

But all through high school definitely, yes, I mean again I was always taking part, captains of the side you know, so you always get involved and always close to the PE circle. I suppose the relationship you have with PE teachers taking you for out-of-school games and activities is different. [It] is a lot different to just a normal subject teacher. It was more like a out-of-school athlete-coach relationship, you support more on a similar level, not teacher up there, pupil down there, so that was the difference. It's a different relationship to every other teacher, so it's the similar relationship [to coachathlete], cause you play for football teams, it's a similar relation to the manager there, so I suppose it is. . . it's less formal so that's probably a better thing, yes. (Peter)

These, then, are emotionally loaded relationships involving a shift not only in structure, from positional to personal relations, but also in quality, moving from the impersonal, vertical, highly regulated relationship of teacher and student toward a more personal, horizontal relationship in which there is an exchange of equals: the talent of the athlete/player for the expertise/knowledge of the coach. 
For many boys at the core of this physical education circle, this was to have a strong impact not only on their sense of physical being and the "use value" of their skills and dispositions, but also on their beliefs in and about sport career trajectories beyond school, as they heeded the career advice of their physical education teachers. All but one of the men in the study went on to study sports science, at least partly as a result of advice from their physical education teacher, some of whom went as far as advising which university was best to attend. Adrian remembers his teacher's advice very clearly:

I always remember the first time, a parent's evening I suppose, he said I would make a good PE teacher. . it's just, like, stigmatized me for life, because I just think, I can't do it, because if I ever see him again, he'll go, “I told you were going to be a PE teacher.". . . So I can remember him, you know, he actually, I went back and played for their, this football team that he used to run, but he had actually moved on since then so I just missed him kind of thing, it was a shame because I would like to see him again.

Derek's experiences were remarkably similar:

It's just it was, I always hung around with, I guess, all the rugby boys I suppose, and you'd have your own, because we were like a group, you would have your own relationship with the PE teacher. I suppose because he was a role model you would notice everything that he did and the funny things that he did, and you would have a good laugh at [him].

Well the Head of Department that came in my third year, Year 9, he had a big impact on me. He encouraged me to pursue my teaching career, he helped my rugby a lot and sorted out a lot of my, of what my best position would probably be, oh he had a massive impact on me.

These relationships represent the channels by which a whole range of social practices and subcultural orientations are transferred. In demonstrating his ability and sustained enthusiasm, Derek was encouraged to become a physical education teacher himself by his former department head. What is important here is how he, as a pupil like the others in the study, became initiated into the organizational hierarchy of the sporting life at school. They not only played sport and did physical education but were also given responsibilities, encouraged to organize activities, become involved in running school teams, and so on. In effect they were invested not just with authority but with added power over and above that of their less able peers. All of these cultural accoutrements of being "top dog" were also tacit initiations into the life worlds of teaching and pedagogy. As Peter and Joe's comments reveal,

I suppose you get captains of different sports, you get asked your opinion of who gets selected, like who is going to play in the team and things like that really. You felt like you were a part of it all-the group of people who were valued in PE who were good at PE I suppose, and you accepted that you were talented and you would always be that way I suppose, really. (Peter)

For the first 3 or 4 years at secondary school the teachers were, like, if you know if you are going to play for the team you must play for the team, and if you don't then you will be put in detention or whatever it was, very compulsory, even extracurricular training was, you were expected to play. (Joe) 
Like the others here, Joe experienced as normal a series of dominant, authoritarian pedagogies that were sport- rather than PE-orientated. While many of the participants later came to question the appropriateness of using these pedagogies in all contexts of physical education and sport, they nevertheless had acquired the direct experiences of how and why these approaches might be deployed and what were "legitimate" qualities to be held by male physical education teachers. These "ways of being" amount to a pedagogy that is reinforced around a gendered persona that includes: demonstrable practical sporting ability; a competitive sports orientation; informality; fun, jokes, and pranks; spontaneity; strength and independence; strong discipline when necessary; and an implicit demand for respect based on these qualities. The participants considered these attributes as qualities of their former physical education teachers. Peter's comment is typical:

I don't know where it came from, probably from a PE teacher I had at school and just the impression... Although I don't actually know where you get it from, the impression you build up of what PE teacher of stereotyping, brilliant at every sport, not show a sign of weakness, being detached from the group and being a pivotal character. And that's, I would work now the completely opposite way to that, if I don't know sport it's best to learn with the children you are teaching and work that way. So I suppose it just came from the stereotypes of PE teachers, not particularly one source, but everything you know about PE teachers.

However, neither Peter nor the others in the study present a counter position or work differently from their former physical education teachers, as we shall see later. Some of this data, then, is strongly suggestive of earlier, seminal, sociological work by Lortie (1975) on the occupational socialization of teachers. In particular, Lortie's apprenticeship-of-observation theory, which considers the influence of student experiences on individuals who become teachers, is of particular interest here in making sense of these teachers as cultural conduits. The crux of the issue for us, however, is the embodied, gendered nature of this influence, and it leads us to consider the nature of the transference of values taking place in this process. Lortie (1975) has this to say:

It is improbable that many students learn to see teaching in an ends-means frame or that they normally take some analytic stance toward it. Students are undoubtedly impressed by some teacher's actions and not by others, but one would not expect them to view the differences in a pedagogical, explanatory way. What students learn about teaching, then is intuitive and imitative rather than explicit and analytical; it is based on individual personalities rather than pedagogical principles. (p. 62)

Nevertheless, we strongly agree with Schempp (1989) that "it is important to remember that the apprenticeship is an influential experience, not a deterministic one" (p. 16). His work on physical education teacher socialization suggests that "teachers do not view their students as the next generation of professional educators, and thus they do not see themselves as master craftspeople training their successors" (p. 14). However, our evidence suggests that a small number of male students, who have come to occupy the inner circle of physical education and school sport participants, may be singled out as potential future educators. At the very least the suggestion must be that physical education teach- 
ers, quite understandably, are recruiting the type of boys they think will make good teachers, and subsequently share their professional and subcultural knowledge with them more freely. These insights are strongly suggestive of an intergenerational process in which key gendered attitudes and dispositions not just about sport and physical education but also about ability, the body and self, are passed on to those able and willing to listen and learn. Lortie's (1975) views are again relevant in this respect:

It is more a matter of imitation, which, being generalized across individuals, becomes tradition. It is a potentially powerful influence which transcends generations, but the conditions of transfer do not favor informed criticism, attention to specifics, or explicit rules of assessment. It would take complex research to confirm this analysis. (p. 63)

The reproductive impact of teacher presocialization, clearly identified in Lortie's (1975) research, offers a salutary reminder to those addressing issues of equity and gender in initial teacher training in physical education (ITTPE):

Unless beginning teachers undergo training experiences which offset their individualistic and traditional experiences, the occupation will be staffed by people who have little concern with building a shared technical culture. In the absence of such a culture, the diverse histories of teachers will play a cardinal role in their day-to-day activity. In that respect, the apprenticeshipof-observation is an ally of continuity rather than of change. (p. 67)

With these insights in mind, we move to identify the second link between generations of physical education teachers, that between the student teacher and his school mentor.

\section{The Student-Teacher/Mentor Link: Learning Gendered Pedagogy}

Processes within ITTPE, it seems, do little to counter or break this cycle of gender reproduction. Schempp and Graber (1992) conclude from their research that within ITTPE, student "teaching practice" in particular tends to be powerfully reproductive in orientation: "Student teaching as a teacher preparation exercise lends stability to the status quo rather than serving as a vehicle for improving practice" (p. 339). Bearing these and Lortie's conclusions in mind, the context of ITTPE in England and Wales gives some cause for concern because subsequent generations of teachers will be trained increasingly in the schools.

With much of the instruction for ITT now taking place in schools, there may be more potential for the processes of secondary socialization within them to further build upon and legitimize the student teacher's already gendered biographical experiences of the differentiated social and cultural aspects of sport. Interaction with a small number of qualified professionals, i.e., the mentors, who are charged with the task of supervising and teaching the teachers, may be instrumental in this process. Building on the "apprenticeship of observation" relationship enjoyed in their own careers as pupils, the visceral, corporeal imprint of prior experience may combine with the new experiences of school teaching to form a highly influential practical pathway toward becoming a male teacher of physical education with the "right" dispositions and skills. 
The period and process of becoming a teacher might be the nexus of a cycle of social construction and legitimation, a process in which the individual biography and embodied capacities of the student teacher meet the institutional discourses and practices of schools, but mediated in important ways by the mentors. The two must become acceptably aligned if the student is to pass through the process successfully and qualify as a teacher, with the onus on the student to accept and practically engage with what is asked of him. Practical knowledge and experience have become the primary media for embedding knowledge, skills, and attitudes in this profession, and it stands in opposition to the relatively high cognitive bias of the university-based component of the course, a point to which we shall return later.

Therefore the student-teacher/mentor link presupposes the transmission, from one generation of teacher to the next, of pedagogical qualities and strategies assumed essential for teaching physical education. Whatever our attitude toward what is passed on through these channels, we have to acknowledge that the directness/immediacy and intentionality of the transference is now a powerful, important, and overt process in the PGCE ITE route into the physical education profession, and future research needs to address this in greater detail and with reference to a whole range of issues. Given this context, the rich vein of research already available on professional and occupational socialization is extremely useful in making sense of the experiences of the men involved in our study (see Lawson, 1983; Lortie, 1975; Templin \& Schempp, 1989).

However, the issue here is more concerned with making visible the legitimation and negotiation of the deeply gendered aspects of the embodied identity, of both self and others, which in turn are seen to influence dispositions and orientations toward ability, performance, and behavior in physical education and school sport. Of particular interest to the study of gender is the way in which the student teacher is both tacitly and explicitly encouraged to absorb the lessons of gendered pedagogies - approaches to teaching that draw on gender stereotypical knowledges and practices - in the classroom and justify them in terms of a broader discourse defining the pragmatics of teaching in specific contexts, such as mixed- or singlesex physical education. As is argued elsewhere (Brown \& Rich, 2002), physical education pedagogy is rarely socially neutral; it subtly positions everyone in the situation in relation to dominant assumptions about sex and gender, constructed from a particular patriarchal ideology of a gender order (Connell, 1995; Messner $\&$ Sabo, 1990). For example, Derek noticed the subtle flow of knowledge and dispositions that came from his school mentors:

I think you learn the little things sort of within lessons and sort of being able to do things without thinking about it generally, more than one thing at a time. Yeah, see it comes so natural to them, and you pick up little things. How they relate to the children as well. That was the main area.

The naturalness and practiced performances of the mentors' pedagogy were immediately reassuring to these men. Their teaching approaches were reported as seamless with their own presentation of self, and they were seen as being themselves and behaving naturally in the classroom, something that many of these men aspired to do and a topic to which we will return later. Our data suggest that mentors were legitimating gendered pedagogies. Peter comments on the range of strategic skills and dispositions acquired in the transmission: 
I mean I picked up so many different things, just on content of lessons, different practises to make the lesson itself more active, the styles you teach, I mean I definitely picked up some indications to try and be yourself but pick up more things to put them into your mix, but definitely styles, approaches to the pupils, approaches to different lessons, how you treat activity subjects, how you [approach the] teaching of tennis which is quite complicated as opposed to teaching of football, where perhaps pupils are more able to see different approaches and different ways of relating to the pupils who are giving you a hard time, how to treat, how to recognize different types of sort of misbehavior if the pupils are just trying it on or if you actually got a serious problem and you, it needs to be. . . but loads of, so many different things you can actually do.

He added, "I think when you first start, you definitely pick them up, and as you become more confident in your own teaching I think you assimilate those into your own style." The lessons learned here are crucial validations of how to relate to children in the real world and what is acceptable gendered male behavior in front of children and what was not, as Derek's comments depict:

Yes, I saw that with my mentor especially, the more caring side, with the girls you would tend to have to be a bit more mothering, um not so macho then perhaps, tone that down.

[Interviewer]: Yes, did, that's interesting, did the boys respond presumably to that more, are they expecting that?

Yes.

[Interviewer]: Well they might look at you and think you know.

Yes, that's perhaps what they were expecting...

[Interviewer]: Or not, I don't know?

Yes but there are boys there who would respond better to the quiet word, the quieter approach as well, whereas with others you have just got to get on top of them, you have got to be a bit macho, to get you know [control and respect].

Clearly the knowledge and dispositions passed on can either legitimize or subvert enactments of dominant masculinity in the classroom, and it is clear that for some of these men the mentors' dispositions were shared in quite persuasive ways, as Trevor's comments about his mentor reveal:

Yes it was an all boy, it was comprehensive but a comprehensive boys school. And he was good, he always, like, said "Oh you're too nice, you got to be this, that and the other," do know what I mean. And I think part of that was it was just my first experience of teaching.

Trevor's comments, further illustrating the intentional shaping of how to act in front of the children, is a central focus of the mentor's advice. He saw him as a good, strong teacher, noting, "the first mentor at [boys school], he was excellent, he was a quite hard taskmaster, he was like old authoritarian schools, he was quite old fashioned." Again we see that the link between mentor and student teacher is not only pedagogical in content but also implicitly gendered socially as well. To be certain, the link with the mentors can be both a force for challenging and reinforc- 
ing gendered practices, and in this data set at least, the approaches a student experiences seem arbitrary in their distribution. On balance, however, the apprenticeships witnessed here reinforced and legitimated conventional patriarchal, gendered pedagogy and did very little to challenge underlying biological or social assumptions about boys and girls.

\section{The Second-Generation Teacher/Pupil Link: Reproducing Gender?}

On the surface, having succeeded in gaining qualified status, these male student teachers are free to practice their physical education as they see fit, except of course they are not at liberty to resist or contest the views and experiences they have witnessed! The stories they tell about themselves as teachers now reflect their own values quite strongly, but these values are clearly ones they have absorbed throughout their gendered experience of physical education and school sport thus far, re-storied and re-represented as a part of themselves. Hence, in terms of our notion of intergenerational transmission, these teachers have become living links or cultural conduits, passing on socially inculcated dispositions to another generation of pupils, as the following extracts illustrate:

So I want to go into a school and be someone that kids can talk to, someone that they can learn from, someone that they want to listen to or maybe they can learn a few things about PE, about growing up, about handling themselves, about respecting themselves, about doing what they want to do, and about meeting challenges, which is, I mean, that's what it's all about, whether it's PE or whether it's anything else so. I want, I feel quite strongly that I could be a good teacher, and then and sport because I love sport, I'm enthusiastic about sport. (Trevor)

I suppose in terms of what gets passed on my, you know, knowledge and when I was teaching rugby, football, athletics, whatever it was and the knowledge I had. You know I wasn't going to withhold any. I was always going to give it what I could, in terms of advice for life skills. (Shaun)

I think what it needs to be, is to be able to work with children I always get a great buzz working with, passing on all the knowledge and experiences I have had in PE, you know, reflecting on the negative ones and perhaps trying to shape those into the way I teach and try and think about those as you do teach, and you know, think about the sport for all, especially participation, and I want everyone to have positive experiences in my classes. Perhaps focus extracurricular on the better players or the better sportsman of whatever sport because there is a temptation to focus on those even in the PE class, and I think that is wrong sort of focus onto the PE more than the sport, we conceptualize it as sport sometimes too much. (Derek)

Well, I teach something that the kids enjoy. The reason I do that is because I enjoyed it myself, enjoyed learning sport and that's the only thing I can see is how I would teach. (Alan)

What is noticeable about these comments is that they all draw strongly on these men's own biographical experiences of sport and physical education. For 
example, Alan's interest in fun was how his school approached physical education and sport and how he was encouraged to view it. Derek feels that through his involvement in sport he gained a lot of self-confidence and respect, as well as social mobility. His interest in extracurricular sport reflects his belief that it was here he acquired many of these benefits, and implies this is where he could do the same. In a similar vein, Trevor came into physical education teaching through his elite performance in competitive sport, and it has given him a social mobility that throughout his childhood in the inner city he would not have believed possible. Consequently, both men wish to promote their beliefs about the positive impacts of sport and physical activity. One key disposition Trevor wishes to pass on is that of competition:

I have been criticized for that really, being overcompetitive, especially the secondary school which was trying to shy away from competition, but I don't see the point, life's all about competition. At the end of the day kids need to learn that, and although there are winners and losers in every competition, more than one competition to compete in, you know what I mean, so you might lose at something but you might win at something else. It's important for kids to learn that they are going to have to be competitive, they are going to have to try and win in some areas because if they don't, then they are going to struggle. Although at the same time you have got to make sure they don't label themselves as losers before they have even started.

While we in no way question the abilities of Trevor or the others as teachers or their best intentions for all their pupils, these extracts bear the biographical imprint of a lifetime's successful investment in the masculine arena of sport. As such these men represent a living link between the past, present, and future, a cultural conduit for the legitimate (i.e., state sanctioned) masculine ways of interacting in the world of sport, physical activity, and beyond.

This link, we feel, becomes all the more pertinent when these men describe how they negotiate gender in their approach to teaching physical education. Here Schempp and Graber's dialectical perspective of teacher socialization is again helpful in making sense of these men's stories. Schempp and Graber (1992) refer to the dialectical process in this context as, "a process involving the confrontation of contending propositions that ultimately resolve into a synthesis of perspectives and actions of a new and unique design" (p. 330).

Schempp and Graber also remind us that the dialectic does not end when teachers qualify and begin their careers in schools. They note, "as teachers live their lives in schools, they both shape and become shaped by the experience. So on it goes" (p. 344). In light of Schempp and Graber's perspective, we can begin to see the subtle and not so subtle negotiation of gender in evidence in each of these men's stories. Negotiating gendered pedagogies that involve personal, emotional, and identity resources requires a considerable degree of resolution of values, dispositions, and roles demanded by the institution and held by the individual. It also requires a pedagogical approach that is prepared to be flexible with the presentation of self and relatively responsive to others. Peter reflects on the links between his generation and that of his physical education teacher:

I would hope for me to take some small bits of my old PE teacher because I think he had a really good knowledge base, his knowledge of all sports was 
really excellent. I think what I would like as a peer now is I would want to try and communicate much better with children, to try and be closer to them because I think he was quite detached and I don't think that really works. And I'd like to be, sort of communicate at a, not a more even level but actually feeling for their views and their weakness or whatever as well. Because I think that is perhaps one thing that is tied to the past, not really good communicators. Not especially good motivator of other people who weren't particularly strong at the sports, or strong at PE, I don't think he motivated those people.

I think that perhaps PE teaching has changed, maybe it, I think that perhaps he is a product of a system that their teacher training sort of, sort of forced them to be like that. I was talking to the deputy head in the school, he used to be a PE teacher and he talked about lining children up for these sort of punishment things, and I perhaps think now they were a product of a teacher training that molded them to be that way-this is how the PE teacher is. And I think that has changed now, I think there is a lot more flexibility too.

However, as we shall see, Peter's process of negotiating his gendered pedagogy in the classroom leads to a synthesis of pedagogies which, under the everyday pressures of teaching, means resorting pragmatically to dominant masculine approaches in order to survive:

I think especially for a new teacher [in] a new environment, I think I felt it was important to establish yourself. I suppose that by "establishing yourself" I probably mean a masculine PE teacher. And as time goes by, the other teachers then, were able to not need to use that as much because. . . If they needed to they could use it, but they wouldn't use it frequently and I felt that perhaps I needed to use it a little more, to try and get a kind of distance between the pupils to start with, to establish that role, "me-teacher, youpupil" kind of role. Then move closer from there, I actually felt that as I started to be sort of close, without establishing the roles, that didn't work so I had to come out, and go back in again.

Here Peter has clearly learned from others how to be and act at certain times. Moreover, he has the gender resources to negotiate this gendered pedagogy in the classroom, in order to gain control and the respect of key pupils. What is also evident is the way in which most of these men, at various points, draw on their former physical education teachers or mentors as a point of reference:

I did to start with [it was] quite difficult to change between the two at the start. Not wanting to be seen as sort of my old typical PE teacher, but then realizing that at times you have got to be like that as well, when the situation dictates that sometimes you have to be like that, and getting the balance between switching back to a role that perhaps I favor more in teaching.

Importantly, although Peter as well as many of the others considers that the dominant approach is not really "them," he adopts it because it works as an effective coping strategy in difficult circumstances. The context goes some way toward justifying the response of Derek, who makes reference to his own physical education teacher's masculine pedagogies as something he now understands in a different light and admits to employing similar strategies when necessary: 
And I suppose to survive teaching single-sex PE all the time, you are going to get difficult boys to handle perhaps in a big group. I suppose perhaps that is part of the reason why they developed in that way and they weren't trying things is because it was more of a challenge. (Derek)

Adrian speaks for several of the men when he expresses concerns that his actions in context will result in him becoming a "stereotyped PE teacher, I mean I would just hate to be a stereotype of a PE teacher, but will probably end up being one kind of thing."

\section{Concluding Comments}

The exigencies of teaching physical education in secondary schools in the U.K. are always challenging and often materially and physically badly underresourced. Given this context, conceptualizing gender as an intergenerational process involving living links, with the teacher acting implicitly as a cultural conduit, may help us articulate dimensions of the production and reproduction of gender relations in sport and physical education that are as yet underexplored. These processes remain highly elusive. However, we take the view that people, as embodied, socialized individuals, provide continuity, binding past, present, and future gendered physical education discourse and practice together in ways that defy simple description. These channels might also of course be catalysts for change; however, the data from this research has endorsed Lortie's (1975) and Schempp and Graber's (1992) claim that without significant interventions, transmission in ITTPE will tend toward the status quo.

We have identified three gendered links that appear consistent and significant. First, through the first-generation teacher/pupil link, unlike earlier work in teacher socialization, it appears that PE teachers are implicitly recruiting potential PE teachers and athletes "in their own image," developing special relationships with pupils and exposing them to a range of experiences that seem to have a powerful impact not only on their career trajectories but also on the development of key masculine dispositions toward sport and physical activity. This in turn facilitates their success in the gendered sporting arena and entry to the physical education profession. Second, through the student-teacher/mentor link, these teachers are invested into a second practically orientated apprenticeship where gender beliefs and pedagogies are legitimated, passed on, and practiced. Third, in the second-generation teacher/pupil link we see these teachers actively wishing to pass on to a new generation what they have now internalized as their own masculine values and practices about the importance of sport and physical activity and the correct way of being a male within it. They actively engage in processes of tacit negotiation with pupils and their schools over which pedagogies are most appropriate to adopt, a situation that leads them to draw on dominant masculine approaches to assert themselves as successful male teachers.

This paper provides only a small contribution to our understanding of issues of continuity and change of gender relations in school sport and physical education as mediated through embodied people rather than discursive structures alone. If nothing else, the discussion clearly demonstrates that there $i s$ a gendered dimension to the channel of influence that runs between generations of physical eduation professionals, and that the change in teacher education to a strongly school-based PGCE route in effect trains teachers in ways that maximize the transmission of 
knowledge between generations of teachers. As such, this corroborates with work by Hardy (1999), who found a great variability with the mentoring process and that the complexities of teaching were being replaced with more simplistic perspectives. There has been rather less space for articulating specifically what these channels might actually transmit, although, as we have indicated elsewhere, much of what is learned in the process is strongly gendered in orientation (Brown, 1999; Brown \& Rich, 2002).

Clearly, further empirical research is needed to document the processes described above in order to make our understandings truly intergenerational. This would logically involve tracking generations of physical education teachers, and perhaps influential others, to build something akin to a genealogy of what in the form of social relations, attitudes, and predispositions is being passed on, and how, when, and why. Furthermore, such an approach would allow us to identify significant ruptures in the anticipated reconstruction of gender through the physical education teacher, thereby creating the possibility of examining sociocultural change as well as continuity.

An intergenerational approach would also need to broaden its focus to include those factors outside the professional arena that provide strong contexts and resources for action. These would include exploring the individual's socioeconomic and ethnic background as well as his familial and peer group. Equally it needs to explore in much more detail what knowledge is being passed over in the university part of the PGCE course, and the student-teacher reaction to it, as the evidence here is that the large practical experiential element has reduced its impact. Finally, we would acknowledge that for the purposes of conducting this kind of research, one might need a broader range of methods. A combination of indepth interviews and observational research might provide a more powerful data set with which to develop these insights.

For an intergenerational approach to flourish, we are also likely to require a wide range of conceptual tools in order to articulate these genealogies in sociological terms and at a variety of levels from the micro to the macro. These might help us link and situate many of the perspectives already developed in the occupational socialization literature in and coaching with those of mainstream sociology. Two examples are worth noting here. Lortie's apprenticeship-of-observation thesis is strongly suggestive of Bourdieu's $(1990,1998)$ theory of practice. Lortie suggests that prospective teachers absorb and imitate values and embodied dispositions through practical engagement, and thereby come to embody and identify the profession of teaching. This has strong parallels with Bourdieu's conceptual triad of habitus, capital and field and its reproductive orientation (Bourdieu, 2001; Grenfell, 1996; Grenfell \& James, 1998).

Similarly, Schempp and Graber's dialectical perspective might be situated within the broader processes of change outlined in Gidden's $(1990,1994)$ theory of institutional modernization. This would allow us to better articulate the processes of negotiation between individuals and institutions that are in a constant state of transformation, and thereby recognize the interconnectedness of individuals, their biographies, embodied dispositions, and the wider social order in which they are situated. Finally we need to understand the everyday gendered positiontaking and assigning of teachers, mentors, and pupils as they engage with one another. In this we might benefit from looking simultaneously at the work of Connell (1995) on gender order hierarchies and Goffman's (1983) interaction order for 
guidance on how together they might add further texture to the dialectical perspective mentioned above.

The process of becoming a teacher is an important one for the social construction of gender relations in physical education and school sport and beyond. How dispositions of hegemonic masculinity are recognized, recruited, and then worked upon by and through teachers remains an important task for sociological and professionally oriented research. Clearly, if we are to better understand the social construction of gender and gender relations, we have to better understand teachers and the embodiment of self, and ultimately search out the implications of these processes for pupils' sense of achievement, body, and identity. In this vein we stress that the data presented here have foregrounded the production and reproduction of a particular form of masculinity, hegemonic masculinity (competitive, heterosexual, hierarchical, and positional), but we have not been able to articulate its attendant capacities to marginalize or subjugate other forms (see Connell, 1987; Mac an Ghaill, 1994; Willis, 1977) that may enter but fail to find expression in education, physical education, and school sport.

It is perhaps also worth noting that we write this paper at a time when the "underachievement of boys" in schools in the U.K. is causing some concern among politicians and educators, the argument being that "laddish culture" is at least partly to blame. Boys in (some) schools, it is claimed, are seen as immature and selfcentered, demanding and dominating, constructing their masculinity through overt heterosexuality and homophobia, physical segregation, and violence. In the school context, "this laddish construction of masculinity is often in opposition to the values of the school, and is seen to be incompatible with learning" (Younger, 2002, p. 2; also see McLellan, 2002).

While we have no wish to endorse the flawed rhetoric that boys (a thoroughly undifferentiated category in much of this debate) are now more deserving of attention than girls, or that laddish culture alone is at the root of their underachievement in schools, it does raise important issues for teachers and mentors in physical education. Are they, through the processes described above, implicated in the production of laddish culture? And if so, who benefits and who is disadvantaged academically and corporeally, not only in physical education and school sport but also in the wider curriculum of schools?

\section{References}

Altheide, D.L., \& Johnson, J.M. (1998). Criteria for assessing interpretive validity in qualitative research. In N.K. Denzin \& Y.S. Lincoln (Eds.), Collecting and interpreting qualitative materials (pp. 283-312). London: Sage.

Atkinson, R. (1998). The life story interview. London: Sage.

Bourdieu, P. (1990). The logic of practice. Cambridge: Polity Press.

Bourdieu, P. (1998). Practical reason. Stanford, CA: Stanford University Press.

Bourdieu, P. (2001). Masculine domination. London: Polity Press.

Brown, D. (1999). Complicity and reproduction in teaching physical education. Sport, Education and Society, 4, 143-160.

Brown, D., \& Rich, E.J. (2002). Gender positioning as pedagogical practice in learning to teach physical education. In D. Penney (Ed.), Gender and physical education: Contemporary issues and future directions (pp. 80-100). London: Routledge. 
Brown, L. (1997). Boys' training: The inner sanctum. In C. Hickey, L. Fitzclarence, \& R. Mathews (Eds.), Where the boys are: Masculinity, sport and education (pp. 13-27). Deakin: Deakin University Press.

Burgess, R.C. (1982). Field research: A sourcebook and field manual. London: Routledge. Connell, R.W. (1987) Gender and power: Society, the person and sexual politics. Sydney: Allen \& Unwin.

Connell, R.W. (1995). Masculinities. London: Polity Press.

Creswell, J.W. (2003). Research design: Qualitative, quantitative and mixed method approaches (2nd ed.). London: Sage.

Deem, R. (1986). All work and no play? A study of women and leisure. Milton Keynes: Open University Press.

Delamont, S. (1998). You need the leotard: Revisiting the first PE lesson. Sport, Education and Society, 3, 5-18.

Edley, N., \& Wetherell, M. (1995). Men in perspective: Practice, power and identity. London: Prentice Hall.

Evans, J., Davies, B., \& Penney, D. (1996). Teachers, teaching and the social construction of gender relations. Sport, Education and Society, 1, 165-184.

Evans, J., Penney, D., \& Davies, B. (1996). Back to the future: Educational policy and physical education. In N. Armstrong (Ed.), New directions in physical education: Change and innovation (pp. 1-18). London: Cassell.

Fernández-Balboa, J-M. (1993). Sociocultural characteristics of the hidden curriculum in physical education. Quest, 45, 230-254.

Flintoff, A. (1993). Gender, physical education and initial teacher education. In J. Evans (Ed.), Teachers, teaching and control in physical education (pp. 184-204). London: Falmer Press.

Flinotff, A., \& Scraton, A. (2001). Stepping into active leisure? Young women's perceptions of active lifestyles and their experiences of school physical education. Sport, Education and Society, 6, 5-22.

Gard, M., \& Meyenn, R. (2000). Boys, bodies, pleasure and pain: Interrogating contact sports in schools. Sport, Education and Society, 5, 19-34.

Giddens, A. (1990). The consequences of modernity. Cambridge: Polity Press.

Giddens, A. (1994). Reflexive modernization. [with U. Beck \& S. Lash] Cambridge: Polity Press.

Goffman, E. (1983). The interaction order. American Sociological Review, 48, 1-17.

Grenfell, M. (1996). Bourdieu and initial teacher education-A post-structuralist approach. British Educational Research Journal, 22, 287-303.

Grenfell, M., \& James, D. (1998). Bourdieu and education: Acts of practical theory. London: Falmer Press

Griffin. P. (1989). Gender as a socialising agent in physical education. In T. Templin \& P. Schempp (Eds.), Socialization into physical education: Learning to teach (pp. 219234). Indianapolis: Benchmark Press.

Hall, M.A. (1996). Feminism and sporting bodies: Essays on theory and practice. Champaign, IL: Human Kinetics.

Hammersley, M., \& Atkinson, P. (1983). Ethnography: Principles in practice. London: Routledge.

Hardy, C.A. (1999). Preservice teachers' perceptions of learning to teach in a predominantly school-based teacher education program. Journal of Teaching in Physical Education, 18, 160-175. 
Hargreaves, J. (1986). Sport, power and culture: A social and historical analysis of popular sports in Britain. Cambridge: Polity Press

Hargreaves, J. (2000). Gender, morality, and the national physical education curriculum. In J. Nansen \& N. Neilsen (Eds.), Sports, body and health (pp. 133-148). Odense, Denmark: Odense University Press.

Jackson, D. (1990). Unmasking masculinity: A critical autobiography. London: Unwin Hyman.

Kenway, J. (1998). Masculinity studies, sports and feminism: Fair play of foul? In C. Hickey, L. Fitzclarence, \& R. Mathews (Eds.), Where the boys are: Masculinity, sport and education (pp. 155-169). Geelong, Australia: Deakin Centre for Education and Change, Deakin University.

Kirk, D. (1997). Schooling bodies in new times: The reform of school physical education in high modernity. In J-M. Fernandez-Balboa (Ed.), Critical postmodernism in human movement, physical education and sport (pp. 39-64). Albany, NY: SUNY Press.

Kirk, D. (2000). Towards girl-friendly physical education. The Nike/Youth Sport Trust "Girls in sport" partnership project final report.

Kirk, D. (2002). Physical education: A gendered history. In D. Penney (Ed.), Gender and physical education: Contemporary issues and future directions (pp. 24-38). London: Routledge.

Kvale, S. (1996). Interviews: An introduction to qualitative research interviewing. London: Sage.

Lawson, H.A. (1983). Toward a model of teacher socialization in physical education: The subjective warrant, recruitment, and teacher education. Journal of Teaching in Physical Education, 2, 3-16.

Lieblich, A., Tuval-Mashiach, R., \& Zilber, T. (1998). Narrative research: Reading, analysis, and interpretation. London: Sage

Light, R., \& Kirk, D. (2000). High school rugby, the body and the reproduction of hegemonic masculinity. Sport, Education and Society, 5, 163-176.

Lortie, D. (1975). Schoolteacher: A sociological study. Chicago: University of Chicago Press.

Mac an Ghaill, M. (1994). The making of men. Buckingham: Open University Press.

Maxwell, J.A. (1996). Qualitative research design: An interactive approach (Vol. 41). Thousand Oaks, CA: Sage.

Maykut, P., \& Morehouse, R. (1994). Beginning qualitative research: A philosophical and practical guide. London: The Falmer Press.

McLellan, R. (2002, Sept.). Socio-cultural approaches to raising boy's achievement at secondary school. Paper presented at the annual BERA Conference, Exeter, UK.

Messner, M. (1992). Power at play: Sports and the problem of masculinity. Boston: Beacon Press.

Messner, M., \& Sabo, D. (Eds.) (1990). Sport, men and the gender order. Champaign, IL: Human Kinetics.

Miles, M.B., \& Huberman, A.M. (1994). Qualitative data analysis (2nd ed.). London: Sage Moustakas, C. (1994). Phenomenological research methods. Thousand Oaks, CA: Sage.

Nilges, L.M. (1998). "I thought only fairy tales had supernatural power": A radical feminist analysis of Title IX in physical education. Journal of Teaching in Physical Education, 17, 158-172.

Patton, M.Q. (1990). Qualitative evaluation and research methods. London: Sage. 
Penney, D. (Ed.) (2002). Gender and physical education: Contemporary issues and future directions. London: Routledge.

Penney, D., \& Chandler, T. (2000). Physical education: What future(s)? Sport, Education and Society, 5, 71-88.

Penney, D., \& Evans, J. (2002). Talking gender. In D. Penney (Ed.), Gender and physical education: Contemporary issues and future directions (pp. 13-23). London: Routledge.

Plummer, K. (1983). Documents of life: An introduction to the problems and literature of the humanistic method. London: Routledge

Plummer, K. (2001). Documents of life 2: An invitation to critical humanism. London: Routledge.

Pratt, S., \& Burn, E. (2000, Sept.). Every good boy deserves football. Paper presented to the annual British Educational Research Conference. Cardiff, UK.

Rich, E. (2001). Gender positioning in teacher education in England: New rhetoric, old realities. International Studies in the Sociology of Education, 11, 131-155.

Roberts, K. (1996). Young people, schools, sport and government policies. Sport, Education and Society, 1, 47-58.

Salisbury, J., \& Jackson, D. (1996). Challenging macho values: Practical ways of working with adolescent boys. London: Falmer Press.

Schempp, P. (1989). Apprenticeship of observation and the development of physical education teachers. In T. Templin \& P. Schempp (Eds.), Socialization into physical education: Learning to teach (pp. 13-38). Indianapolis: Benchmark Press.

Schempp, P.G., \& Graber, K.C. (1992). Teacher socialization from a dialectical perspective: Pretraining through induction. Journal of Teaching in Physical Education, 11, 329-348.

Scraton, S. (1993). Equality, coeducation and physical education in secondary schools. In J. Evans (Ed.), Equality, education and physical education (pp. 139-153). London: Falmer Press.

Sparkes, A.C. (1989). Paradigmatic confusions and the evasion of critical issues in naturalistic research. Journal of Teaching in Physical Education, 8, 131-151.

Sparkes, A.C. (Ed.) (1992). Research in physical education and sport: Exploring alternative visions. Lewes, U.K.: Falmer Press.

Sparkes, A.C. (1995). Writing people: Reflections on the dual crises of representation and legitimation in qualitative enquiry. Quest, 47, 158-195.

Sparkes, A.C. (1997). Reflections on the socially constructed physical self. In K. Fox (Ed.), The physical self: From motivation to well-being (pp. 83-110). Champaign, IL: Human Kinetics.

Sparkes, A.C. (1999a). Understanding physical education teachers: A focus on the lived body. In M. Mawer \& C. Hardy (Eds.), Learning and teaching in physical education (pp. 171-185). London: Falmer Press.

Sparkes, A.C. (1999b). Exploring body narratives. Sport, Education and Society, 4, 17-30.

Sparkes, A.C. (2002). Telling tales in sport and physical activity: A qualitative journey. Champaign, IL, and London: Human Kinetics.

Swain, J. (2000). "The money's good, the fame's good, the girls are good": The role of playground football in the construction of young boys' masculinity in a junior school. British Journal of Sociology, 21, 95-109.

Talbot, M. (1993). A gendered physical education: Equality and sexism. In J. Evans (Ed.), Equality, education and physical education (pp. 74-89). London: Falmer Press. 
Templin, T., \& Schempp, P. (Eds.) (1989). Socialization into physical education: Learning to teach. Indianapolis: Benchmark Press.

Tierney, W.G. (2000). Undaunted courage: Life history and the postmodern challenge. In N.K. Denzin \& Y.S. Lincoln (Eds.), Handbook of qualitative research (pp. 537-553). London: Sage.

Williams, A., \& Bedward, J. (2001). Gender, culture and the generation gap: Student and teacher perceptions of aspects of the National Curriculum Physical Education. Sport, Education and Society, 6, 53-66.

Willis, P. (1977). Learning to labour: How working class kids get working class jobs. London: Saxon House.

Woods, P. (1986). Inside ethnography and educational research. London: Routledge \& Kegan Paul.

Wright, J. (1995). A feminist post-structuralist methodology for the study of gender construction in physical education: Description of a case study. Journal of Teaching in Physical Education, 15, 1-24.

Wright, J. (1999). Changing gendered practices in physical education: Working with teachers. European Physical Education Review, 5, 181-197.

Younger, M. (2002, Sept.). Raising boys' achievement at school. Paper presented to the annual British Educational Research Conference, Exeter, UK. 